\title{
Well! Am I afraid of dentists?
}

\author{
A Shipley, dental patient
}

Do you think about what it's like at the other end of the drill?

A patient tells it how it is from her point of view.

Preparing to go to the dentist is traumatic in its own right. Have I cleaned my teeth sufficiently, did I remember to floss, does my breath smell? Oh! I wish I hadn't to go, but go I must. Throughout my life I have made visits to the dentist, not religiously every six months but at least every nine months.

As I live in a small village that does not support a dental surgery, I have to drive at least seven miles to the nearest town. This journey I can do without any problems until I am about half a mile from my destination and then it all starts. First I start thinking of all the excuses why I should not go to see my dentist, but the pain in my mouth says I must see him. My heart starts to pound and I find it difficult to breathe properly. I am now at the gate of the surgery. My hands are clam-

I walk down the path towards the door trying to take deep breaths on the way. I feel hot and begin to perspire. I want to turn around and run back to

\section{the car.}

my, my mouth is dry, maybe I should go to a café and have a cup of tea instead. My common sense tells me 'NO! You are here now, ten minutes and it will all be over, but my mind is thinking 'Ten minutes is a long time to a condemned man, but in ten minutes I could be half way home!' I walk down the path towards the door trying to take deep breaths on the way. I feel hot and begin to perspire. I just want to turn around and run back to the car. On second thoughts, I had better not as there is a strong possibility I would just go home. The pounding in my chest is getting stronger. At this rate I will be in need of a cardiologist rather than a dentist.

I ring the doorbell and walk through the door; my legs are now feeling like

\section{In the waiting room, I sit next to an elderly lady. After a} while we begin to talk to each other. She too has clammy hands, a pounding heart and a desire to be elsewhere. jelly. I approach the reception desk trying hard to look cool and collected. The me that my dentist is running approximately thirty minutes late, that is no problem I say whilst shaking in my shoes.

In the waiting room are eight other

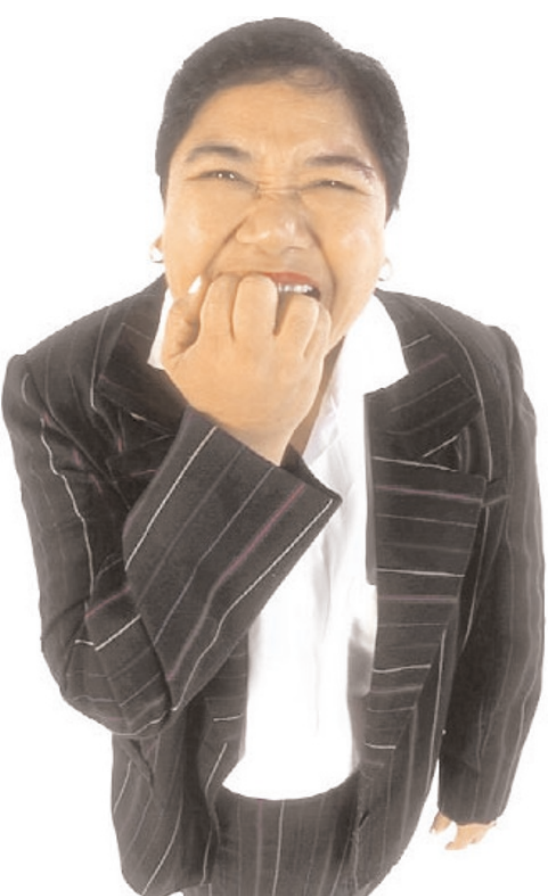
receptionist gives me a smile and informs people; three children, two young women, an elderly lady, a young man and an elderly gentleman. I sit on the seat next to the elderly lady and after a short time we begin to talk to each other. She too has clammy hands, a pounding heart and a desire to be elsewhere.

The drill starts in the consulting room. talking and look at each other and both say, "This is all I need". The children are checked; the young man is treated. All I can think about at this moment is the fact that my turn to go into that room is getting closer and closer. At this point, my hands begin to shake and I think to myself, I wish there could be a power cut and all the electricity would go out. Too late! My name has been called, into the consulting room I walk and there he is in white smock, mask, rubber gloves and wearing goggles over his eyes. What on earth is he going to do? I sit on the chair which is then lowered into a horizontal position. I would defy anyone to try to lever my hands away from the arms of that chair. The dentist prods and pokes my teeth, de-scales and polishes them and brightly informs me that there is nothing wrong with my teeth, the pain is caused by me clenching my teeth together too tightly and he will see me in six months. All that fuss about a mere check up.

Would you say I was frightened of the dentist or just frightened of going to see the dentist? Whichever it is, all I know is that it knocks the stuffing out of a grown woman and makes her wish she had false teeth. 